\title{
KERAJINAN TENUN TRADISIONAL BLONGSONG/TAJUNG PALEMBANG
}

\author{
Indri Ariyanti $^{1}$, Taufikurrahman ${ }^{2}$, Leni Novianti ${ }^{3}$ \\ ${ }^{1,2,3}$ Politeknik Negeri Sriwijaya
}

indri@polsri.ac.id, taufikmesin@yahoo.co.id, leninovianti16@gmail.com

\begin{abstract}
Abstrak
Salah satu Industri tenun tradisional Palembang (blongsong/tajung) merupakan salah satu industri andalan di Sumatera Selatan. Pertumbuhan industri tenun tradisional di kota Palembang (blongsong/tajung) cukup pesat. Masing-masing industri memiliki 2 - 10 tenaga kerja tetap dan juga tenaga kerja lepas.

Di antara usaha kecil dan menengah, usaha kerajinan kain tenun blongsong/tajung Palembang mempunyai karakteristik yang sangat khusus, dan telah menjadi Kebudayaan Indonesia yang tetap bertahan secara konsisten. kain tenun blongsong/tajung berkembang dan menyebar di Sumatera bahkan ke seluruh Indonesia dan mancanegara. Sampai saat ini kain kain tenun blongsong/tajung dengan motif kedaerahan semakin berkembang secara nasional.

UKM Ilham Cha-cha collection dalam pelaksanaan salah satu permasalahannya adalah alat menggulung benang (alat kelos) yang masih dilakukan secara manual. Untuk mengatasi permasalahan tersebut ditawarkan solusi untuk membantu memberikan alat kelos baru yang bisa digunakan untuk menggulung gelondongan benang menggunakan energi listrik, sehingga bisa membantu UKM Ilham Cha-Cha dalam proses produksi. Disamping itu juga diberikan kesempatan untuk mengikuti pelatihan design web sehingga bisa membantu dalam proses promosi UKM Ilham Cha-Cha.
\end{abstract}

Kata Kunci : Industri, Tenun, Blongsong/Tajung, Palembang.

\section{PENDAHULUAN}

Menurut Keputusan Presiden RI No. 99 tahun 1998 pengertian Usaha Kecil adalah: "Kegiatan ekonomi rakyat yang berskala kecil dengan bidang usaha yang secara mayoritas merupakan kegiatan usaha kecil dan perlu dilindungi untuk mencegah dari persaingan usaha yang tidak sehat. Industri tenun tradisional Palembang (songket, jumputan, blongsong/tajung, batik) merupakan salah satu industri andalan di Sumatera Selatan.Pengembangan usaha kecil dan menengah (UKM) merupakan penunjang perekonomian dalam upaya perbaikan perekonomian nasional karena sebagian besar usaha yang ada di Indonesia adalah usaha kecil dan menengah yang banyak menyerap tenaga kerja dan memanfaatkan sumber daya domestik. Jumlah usaha kecil dan menengah (UKM) di Palembang berjumlah 28.766 (Depertemen Koperasi; 2018). Usaha kerajinan kain tenun blongsong/tajung Palembang mempunyai karakteristik yang sangat khusus, dan telah

$$
\text { Teknologi Tepat Guna }
$$


menjadi Kebudayaan Indonesia yang tetap bertahan secara konsisten. Dengan pengaruh motif tertentu, kain tenun blongsong/tajung berkembang dan menyebar di Sumatera bahkan ke seluruh Indonesia dan mancanegara. Sementara itu sampai saat ini kain tenun blongsong/tajung dengan motif kedaerahan semakin berkembang secara nasional.

Salah satu Industri tenun tradisional Palembang (blongsong/tajung) merupakan salah satu industri andalan di Sumatera Selatan. Pertumbuhan industri tenun tradisional di kota Palembang (blongsong/tajung) cukup pesat. Masing-masing industri memiliki 2 - 10 tenaga kerja tetap dan juga tenaga kerja lepas.

UKM Ilham Cha-Cha Collection adalah salah satu pengrajin blongsong/tajung Palembang yang berlokasi di daerah Jakabaring Palembang yang merupakan sentra pengrajin kain tradisional seperti kain jumputan, blongsong/tajung dan songket. Pertama kali usaha kain blongsong/tanjung ini dimulai tahun 1996 dipimpin oleh Bapak Riduan, tetapi hanya bertahan selama 1 tahun. Hal ini disebabkan karena management yang masih berantakan. Modal awal yaitu 1 buah ATBM. Kemudian Bapak Riduan memulai lagi usahanya pada tahun 2007 dengan bekerjasama bersama saudara sampai sekarang. Kemudian di tahun 2017 Bapak Riduan memberikan kepercayaan kepada anaknya bernama Muhammad Ihsan.

Kain tenun blongsong/tajung yang unik dan berkelas ini, ternyata belum didukung dengan fasilitas sarana dan prasarana yang handal. Peralatan utama yang digunakan proses produksi kain tenun blongsong/tajung masih menggunakan peralatan sederhana meliputi ATBM, kelos, hani, bongkar masih sederhana. Sedangkan sistem Manajemen Usaha dan pemasaran yang dijalankan masih relatif sederhana.

Deskripsi produk teknologi dalam kegiatan Program Kemitraan Masyarakat adalah sebagai berikut: Perbaikan teknologi proses produksi peralatan pembuatan kain tenun blongsong/tajung dengan peralatan mesin kelos yang hanya bisa menggulung benang untuk satu gelondongan. Sehingga bila mesin kelos dibuat dengan rancangan bisa menggulung dengan mesin kelos listrik maka waktu yang digunakan untuk menggulung benang bisa lebih cepat. Mesin kelos manual untuk 3 bantalan benang, Dimana dalam 1 bantal $=50$ gulung gelintir selama 2 sampai 3 minggu. Sehingga jika benang kelosan belum selesai maka tidak bisa masuk ke proses berikutnya, apabila mendapat pesanan yang lebih banyak jika terlambat akan mengurangi kepercayaan pelanggan kepada mitra.

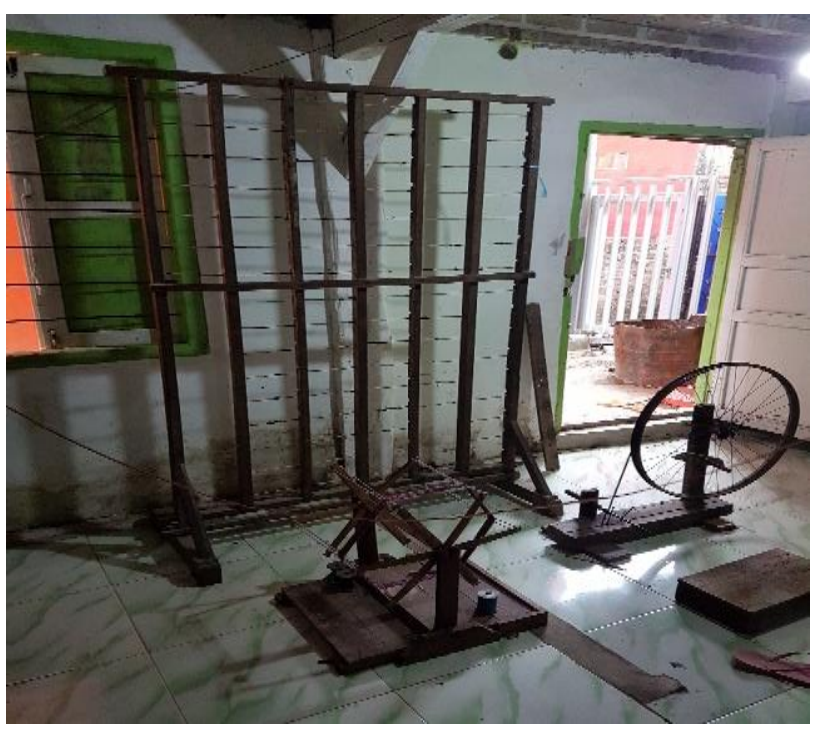

Gambar 1. Mesin kelos manual

Gambar 1. Mesin kelos manual yang digunakan untuk menggulung benang katun. Benang katun di kelos manual untuk 3 bantalan benang, Dimana dalam 1 bantal $=50$ gulung gelintir selama 2 sampai 3 minggu. Sehingga untuk bantalan benang dilakukan selama 6 sampai 9 minggu.

Evaluasi pelaksanaan program dilakukan dengan cara memantau dan memonitor kinerja UKM Ilham Cha-cha Colection secara berkala sejak program Diseminasi Teknologi ke Masyarakat akan berjalan. Selama kegiatan akan dievaluasi sejauh mana solusi yang ditawarkan 
dapat dijalankan pihak UKM. Untuk memastikan kegiatan berjalan sesuai dengan yang direncanakan, akan dilakukan pemantauan

secara berkala per 2 bulan. Jika program berjalan dengan baik maka dapat dilaksanakan kegiatan hingga program selesai dalam tahun berjalan

Bagian-bagian dari mesin kelos manual yaitu:

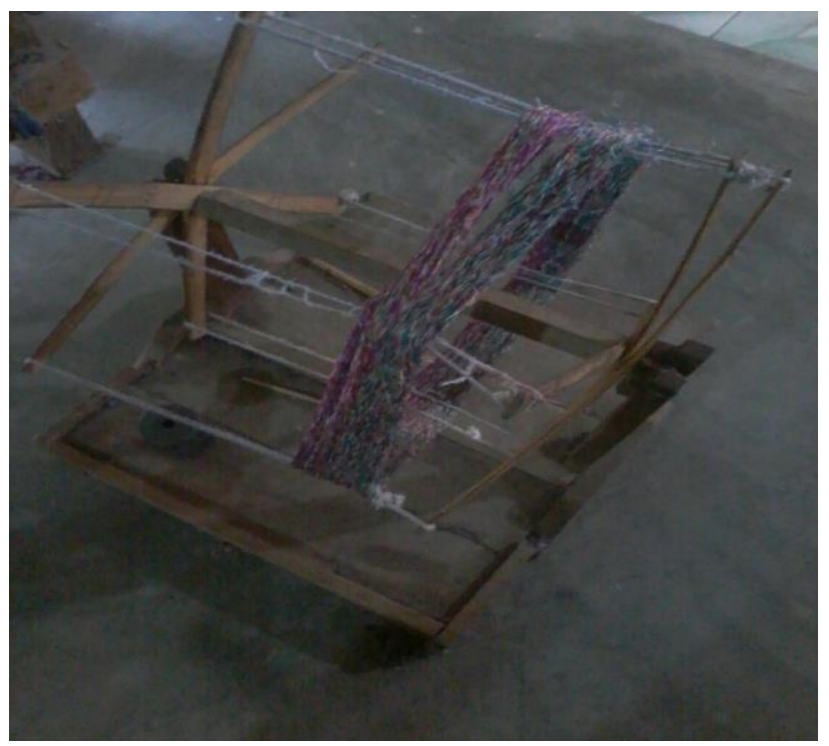

Gambar 2. Jantra

Gambar 2 adalah jantra yang digunakan sebagai tempat memasukkan benang yang belum digulung. Jantra tersebut berputar dengan benang yang tensionnya diatur menggunakan tangan.

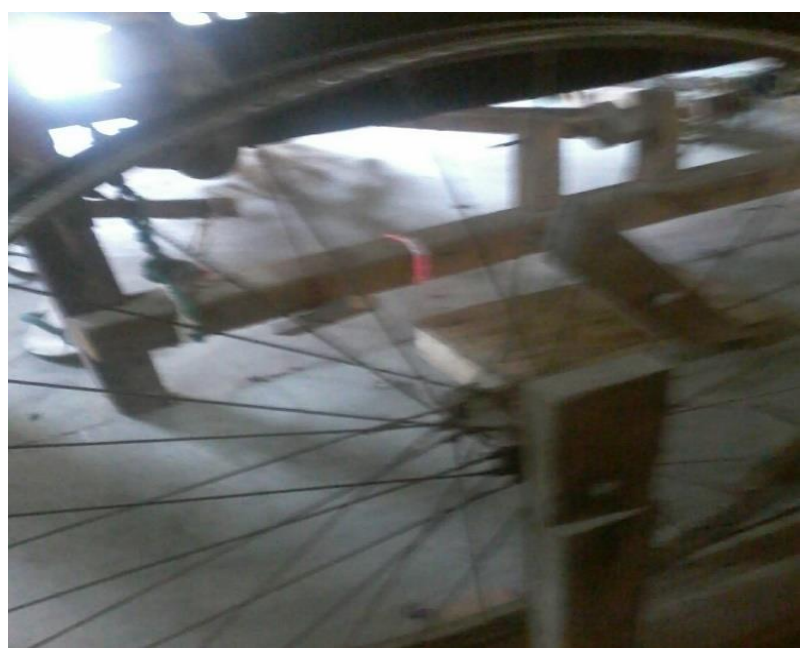

Gambar 3 Velg sepeda

Gambar 3 adalah velg sepeda yang dipasang belt karet untuk memutar alat di gambar 2.

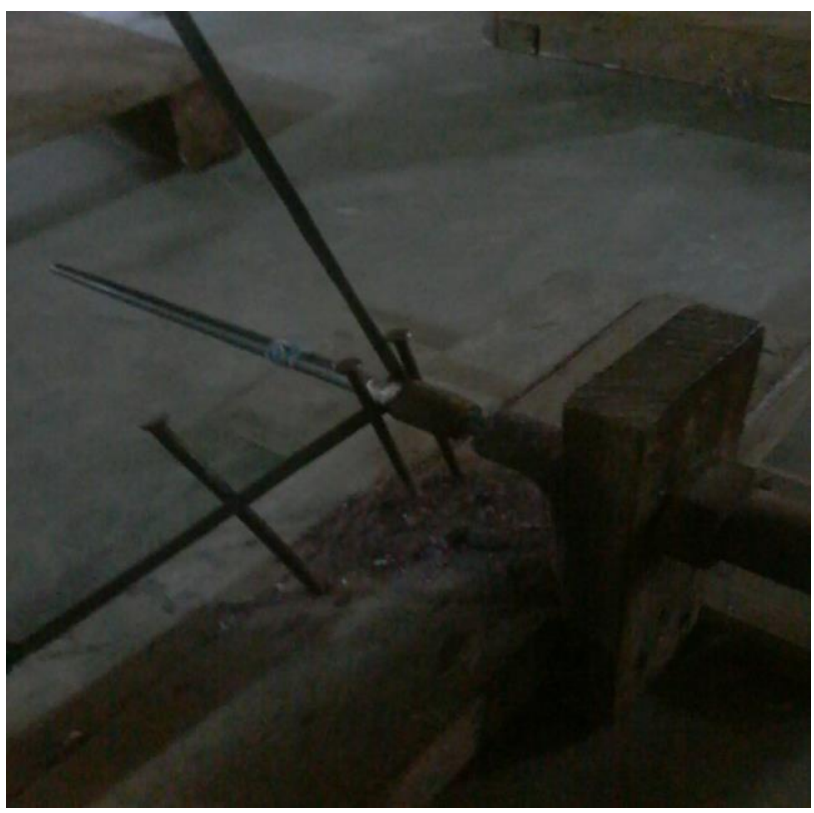

Gambar 4. Gir

Gambar 4 adalah gir yang menggunakan paku tempat untuk memasukkan kelosan. 


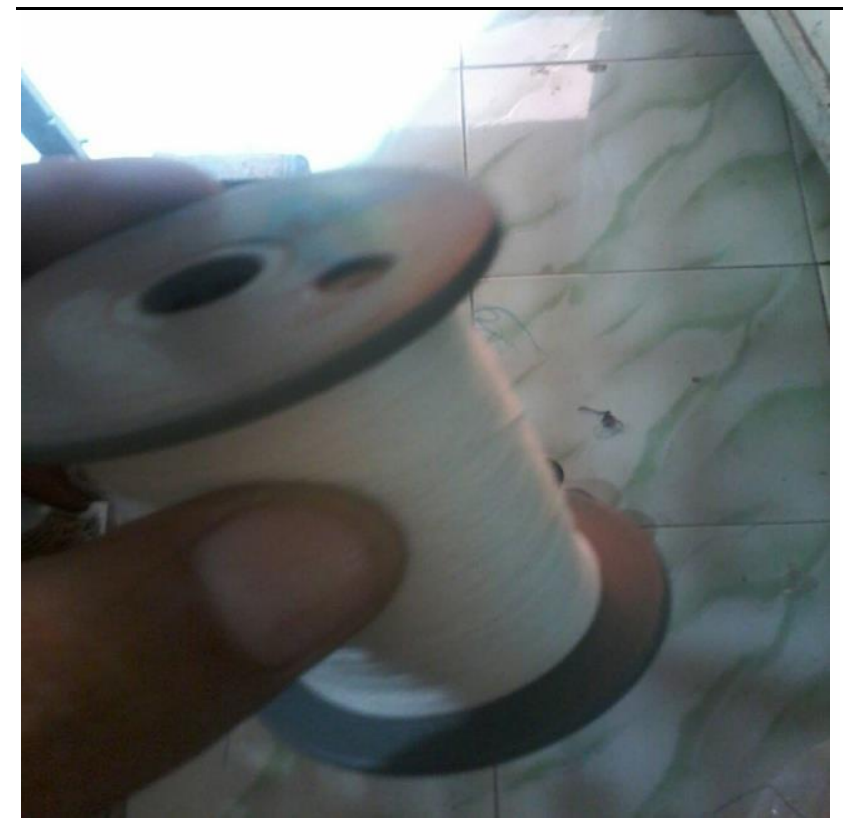

Gambar 5 Benang

Gambar 5 adalah hasil dari kelosan benang yang telah digulung.

Sistem produksi yang dilaksanakan oleh UKM Ilham Cha-cha Collection selama ini masih menerapkan sistem pembuatan kain blongsong/tajung dengan peralatan yang sederhana. Adapun tahapan pembuatan kain blongsong/tajung Palembang seperti berikut ini: Proses pembuatan lusi dimulai dengan bahan baku yaitu benang katun di kelos manual untuk 3 bantalan benang, Dimana dalam 1 bantal $=50$ gulung gelintir selama 2 sampai 3 minggu. Kemudian pindah ke mesin keteng selama 1 jam sampai 2 jam tergantung banyaknya benang. Selanjutnya dilakukan proses pencucukan benang di ATBM. Akhirnya benang tersebut baru di tenun untuk dijadikan kain blongsong/tajung. Dimana dalam sehari ratarata per orang menghasilkan 2 meter kain tenun blongsong/tajung.

Untuk membantu agar penggulungan benang lebih cepat maka dibuatlah mesin kelos listrik.
Langkah-langkah sistematis yang dilakukan dalam kegiatan pengabdian masyarakat antara lain: 1) Identifikasi kebutuhan UKM Ilham Cha-Cha Collection. Identifikasi kebutuhan yaitu proses menggulung benang yang membutuhkan waktu yang lama. 2) Perancangan mesin kelos listrik. Dari permasalahan diatas maka dibuatlah sistem perancangan peralatan produksi yang dapat membantu dalam proses produksi kain tenun blongsong/tajung Palembang yaitu kelos listrik. 3) Pembuatan mesin kelos listrik. Pembuatan kelos sangat dibutuhkan karena dalam proses produksi kain tenun blongsong/tajung pada saat benang dimasukkan ke mesin kelos membutuhkan waktu yang lama yaitu $7-14$ hari, hal ini tentu saja dapat menghambat dalam proses produksi. 4) Pengujian Mesin kelos listrik. Uji operasi mesin kelos dilakukan dengan cara menguji tiap bagian-bagian mesin kelos tersebut. 5) Pendampingan penggunaan mesin kelos listrik. Pendampingan operasionalnya dilakukan secara keseluruhan dalam proses produksi kain tenun blongsong/tajung Palembang penggunaan mesin kelos.listrik.

Untuk menambah pengetahuan akan teknologi melalui web maka mitra di ikutsertakan dalam pelatihan web.

\section{HASIL DAN PEMBAHASAN \\ HASIL}

1. Rancangan Mesin Kelos Listrik 


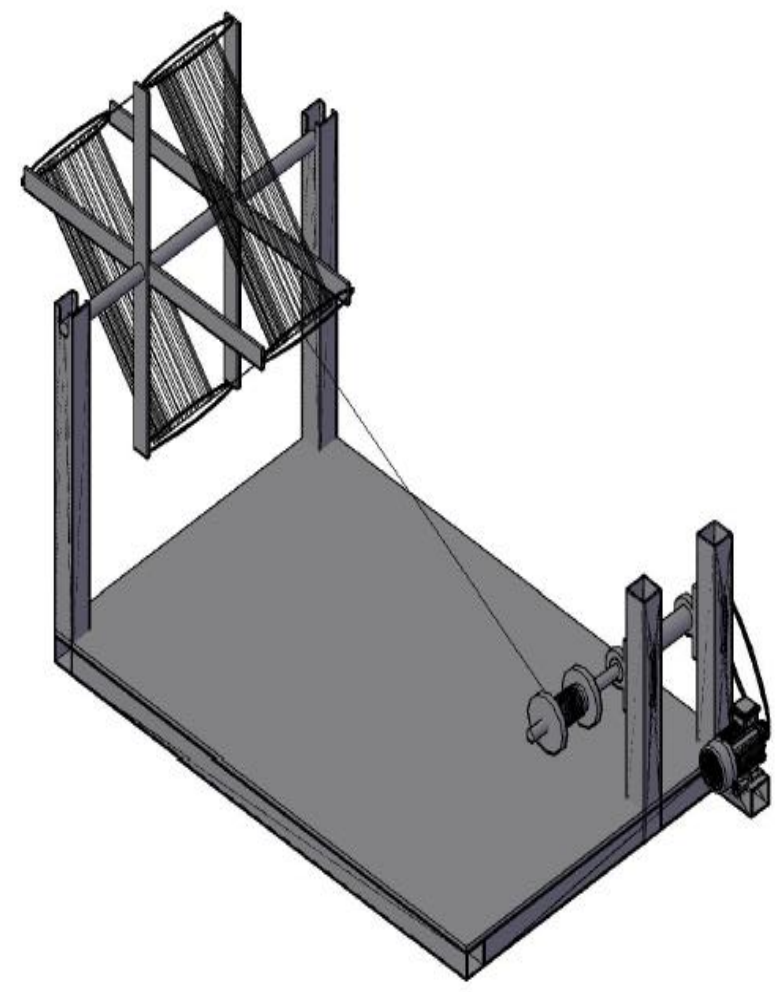

Gambar 6. Rancangan Mesin Kelos Listrik

Dalam perencanaan penggulung benang kain tajung, pertama harus dilakukan pembuatan desain dan prinsip kerja alat tersebut agar dapat dengan mudah dipahami serta mudah dalam pembuatannya. Untuk memperjelas konstruksi alat tersebut dapat dilihat pada gambar 6 .

Pembuatan mesin ini menggunakan beberapa mesin dan peralatan tangan. Dalam proses pembuatan, perhitungan waktu permesianan masing-masing komponen akan dijelaskan. Namun yang paling utama dalam pembahasan ini untuk memberikan petunjuk bagimana alat penggulung benang kain tajung palembang ini dapat dibuat.

Adapun komponen-komponen yang akan dibuat adalah : 1) Frame 2) Poros bertingkat 3) Plat dudukan 4) Dudukan bearing 5) Dudukan uwingan 6) Uwingan.
Tabel 1. Perencanaan Komponen Alat Bantu Penggulung Benang Kain Tajung

\begin{tabular}{|c|l|c|}
\hline No. & \multicolumn{1}{|c|}{ Nama } & Jumlah \\
\hline 1. & Motor Mesin Jahit & 1 buah \\
\hline 2. & Besi Hollow & 1 batang \\
\hline 3. & Sabuk/belt & 1 buah \\
\hline 4. & Pulley & 1 buah \\
\hline 5. & Bearing & 2 buah \\
\hline 6. & Dudukuan Bearing & 2 buah \\
\hline 7. & Poros & 1 buah \\
\hline 8. & Baut dan Mur & 6 buah \\
\hline 9. & Plat Aluminium & 1 lembar \\
\hline 10. & Bambu & 5 bilah \\
\hline 11. & Cat & 1 kaleng \\
\hline 12. & Tempat Gulungan & 1 buah \\
\hline 13. & Benang Kecil (Plastik) & \\
\hline & & 15 buah \\
\hline
\end{tabular}




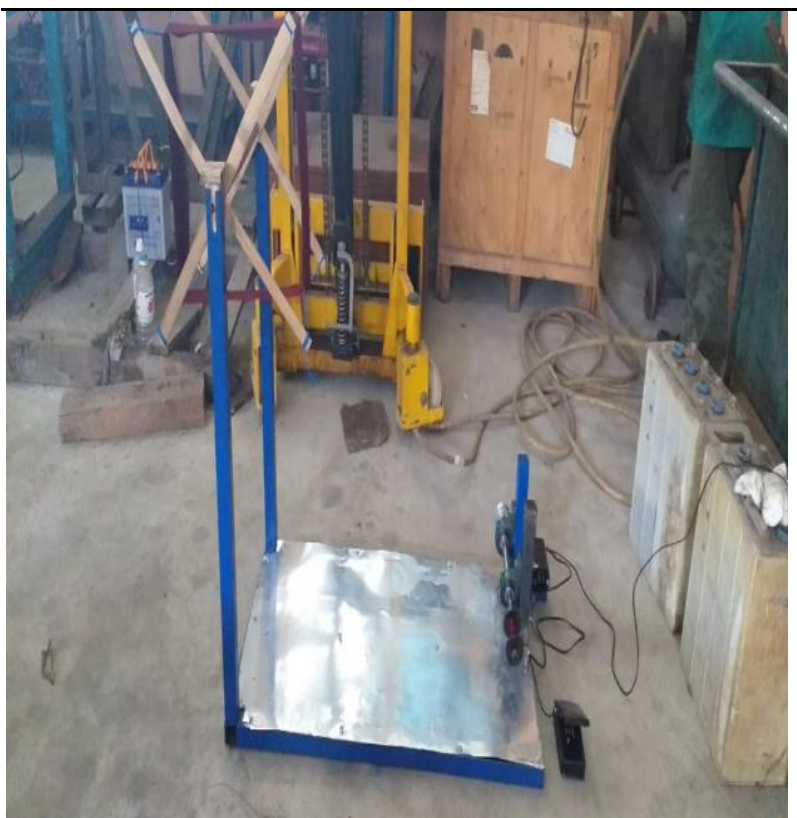

Gambar 6 mesin kelos litrik

3. Bagian-bagian Mesin Kelos Listrik

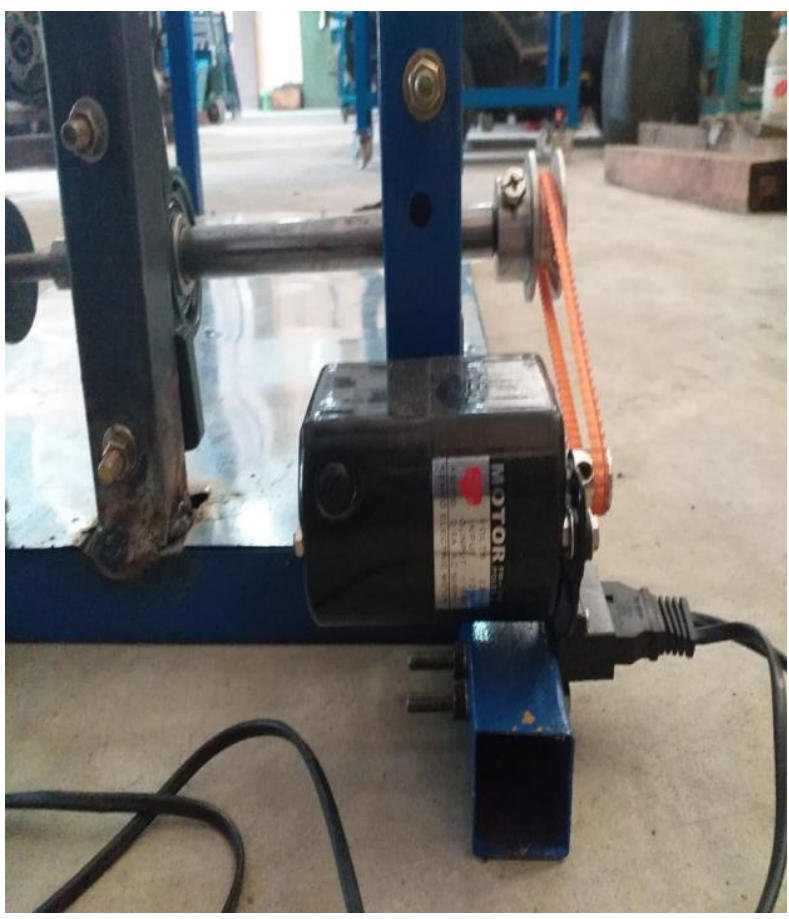

Gambar 7. Motor Mesin Jahit

Gambar 7. Motor mesin jahit memiliki kecepatan putaran yang cukup tinggi serta kecepatannya bisa diatur sesuai keinginan dengan menggunakan dinamo kontrol.

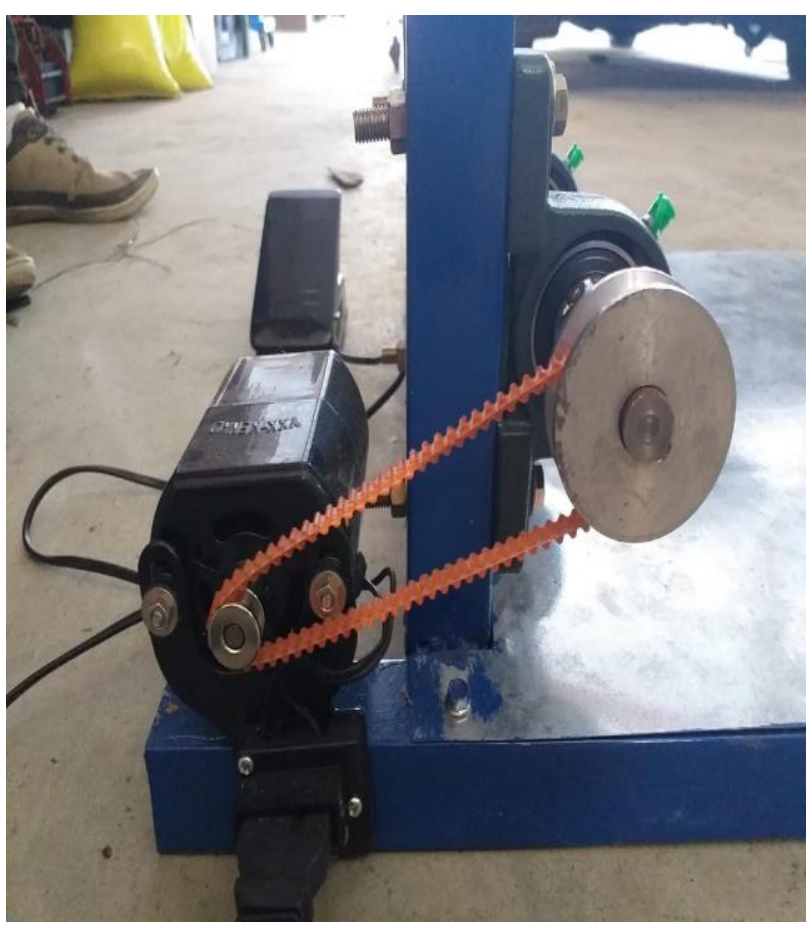

Gambar 8. Sabuk/Belt dan pulley

Gambar 8. Sabuk merupakan elemen mesin yang fungsinya untuk meneruskan daya dan putaran antara dua poros yang mempunyai jarak jauh. Pada alat bantu penggulung benang kain tajung digunakan timing belt yang telah didapat dari motor mesin jahit tersebut.

Pulley adalah sebuah roda dengan bagian berongga di sepanjang sisinya untuk tempat sabuk. Pulley biasanya digunakan dalam suatu rangkaian yang dirancang untuk mengurangi jumlah gaya yang dibutuhkan untuk memindahkan putaran (transmisi daya), pulley yang digunakan pada perencanaan ini sebanyak satu buah.

Sabuk dan pulley dalam perencanaan alat bantu penggulung benang kain tajung Palembang ini digunakan untuk mentransmisikan daya dari motor menuju poros. 


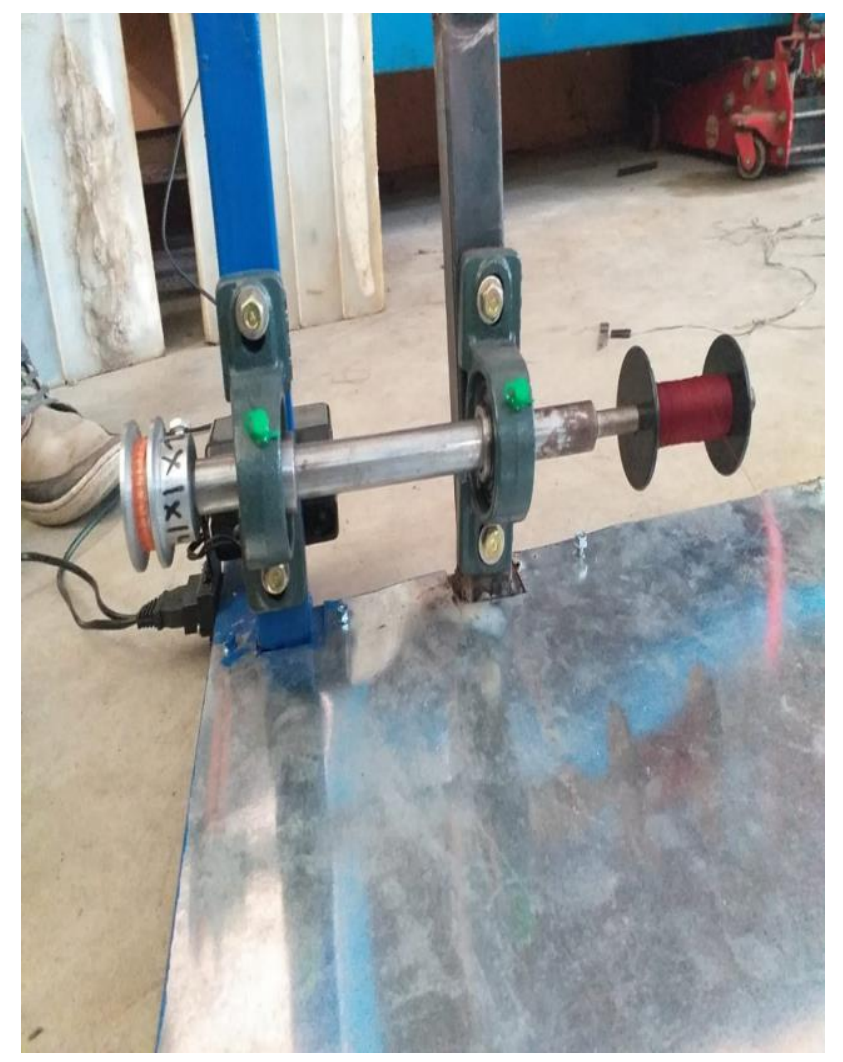

Gambar 9. Bearing, Mur, Baut, dan dudukan bearing

Gambar 9. Bearing adalah suatu komponen yang berfungsi untuk mengurangi gesekan pada mesin atau komponen-komponen yang bergerak dan saling menekan antara satu dengan yang lainnya. Bearing dalam konstruksi alat ini menggunakan journal/slip bearing dengan lubang berdiameter $19 \mathrm{~mm}$ dengan tipe UCP 204-12 sebanyak dua buah.

Dudukan bearing dibuat dari besi hollow dengan ukuran 250 x $40 \mathrm{~mm}$.

Beberapa komponen tidak disambung menggunakan las listrik melainkan dengan baut roofing dengan menggunakan bor tangan agar mempermudah dalam kegiatan maintenance dan memindahkan alat tersebut.

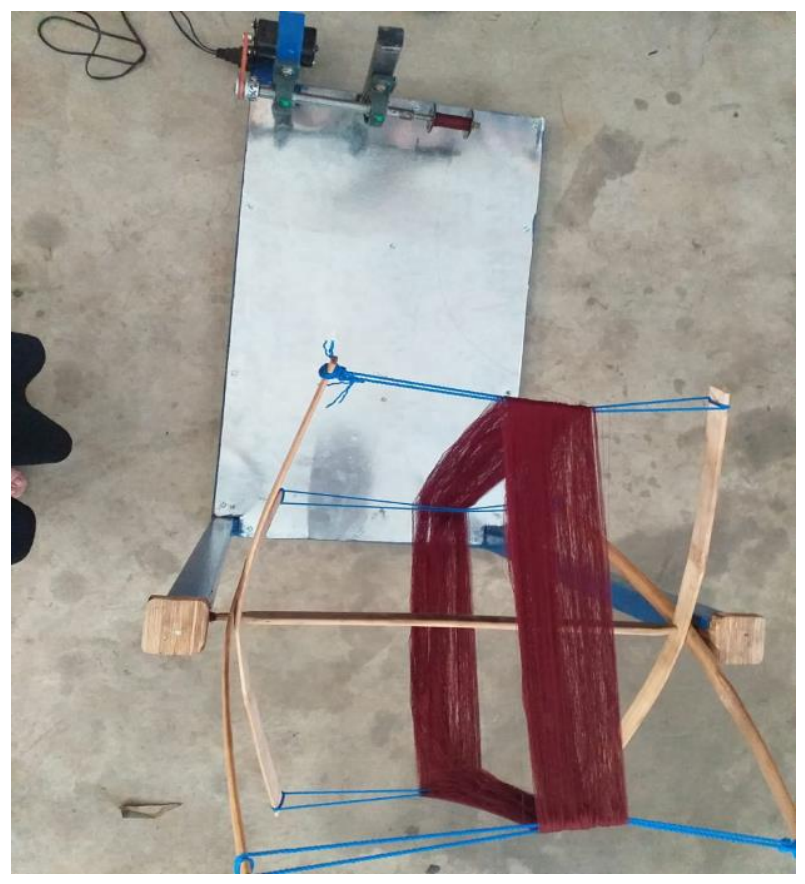

Gambar 10. Benang dan Uwingan benang

Gambar 10. Tempat gulungan benang besar (uwingan) terbuat dari bilah bambu untuk menggulung benang dari pabrik.

\section{PEMBAHASAN}

Mekanisme alat penggulung benang kain tajung Palembang adalah sebagai berikut : 1) Arus listrik mengalir dan menggerakkan motor listrik mesin jahit. 2) Pada motor listrik terdapat dinamo kontrol yang dikendalikan dengan tangan untuk mengatur kecepatan dari motor listrik tersebut. 3) Motor listrik akan menggerakan pulley dan timing belt yang sudah terpasang. 4) Pulley yang terpasang pada poros akan bergerak karena mendapatkan transmisi daya. 5) Pada poros juga sudah terpasang gulung benang kecil yang bisa dilepas pasang. 6) Poros dibuat dengan salah satu sisi dapat di lepas sebagai tempat keluar masuk nya gulungan benang kecil 7) Akibat berputarnya poros, gulungan kecil yang sudah di belitkan beberapa lilitan benang akan memutar gulungan benang besar (uwingan). 8) Proses ini berlangsung terus 
menerus sesuai keperluan dari pengrajin benang kain tajung.

Perbaikan adalah usaha yang dilakukan untuk mengatasi kerusakan pada komponen lainnya. Sehingga mesin dapat kembali beroperasi dengan baik. Dilihat dari bentuk kerusakannya, maka jenis kerusakan dikelompokkan menjadi dua, yaitu: 1) Kerusakan dapat diperbaiki. Apabila komponen mesin mengalami kerusakan dan kerusakan tersebut tidak terlalu parah dan masih dapat diperbaiki. 2) Kerusakan tidak dapat diperbaiki. Apabila komponen mesin mengalami kerusakan dan kerusakan tersebut tidak diperbaiki sebaiknya dilakukan penggantian komponen. Penggantian yang dilakukan pada alat bantu penggulung benang kain tajung Palembang berupa penggantian bearing, pulley, belt, dan lainnya

\section{KESIMPULAN}

Waktu penggulungan benang kain tajung menggunakan alat ini jauh lebih efisien dibandingkan dengan hasil pengerjaan konvensional dan hasilnya pun jauh lebih padat. Hendaklah dalam pembuatan alat ini harus didasari pada bentuk, variasi, dan inovasi yang cukup menarik agar dapat menciptakan daya tarik tersendiri.

Perencanaan komponen yang akan digunakan sangat penting dilakukan sebagai acuan untuk melakukan proses pembuatan agar efisien tan tepat sasaran.

\section{SARAN}

Jika terjadi kerusakan pada alat ini, segeralah lakukakn perbaikan agar kerusakan yang terjadi tidak bertambah ddan alat ini dapat digunakan kembali.

Diperlukan pengembangan lebih lanjut agar alat ini benar-benar dapat diterima dipasaran.

\section{UCAPAN TERIMAKASIH}

Ucapan terimakasih disampaikan kepada Kemenristekdikti melalui Program Kemitraan Masyarakat (PKM), Politeknik Negeri Sriwjaya, serta rekan dosen serta mahasiswa yang telah memberikan kontribusi dalam pelaksanaan kegiatan.

\section{REFERENSI}

Departemen Koperasi. 2018. Rapat Koordinasi Nasional Bidang KUMKM Tahun 2018. Yogyakarta.

http://www.depkop.go.id/uploads/tx_rtgfiles/18 ._Paparan_Rakornas_Yogya-karta_2018_-

Sumatera_Selatan.pdf

Keputusan Presiden Nomor 99 Tahun 1998. Tentang Bidang/Jenis Usaha Yang Dicadangkan Untuk Usaha Kecil Dan Bidang/Jenis Usaha Yang Terbuka Untuk Usaha Menengah Atau Usaha Besar Dengan Syarat Kemitraan. 